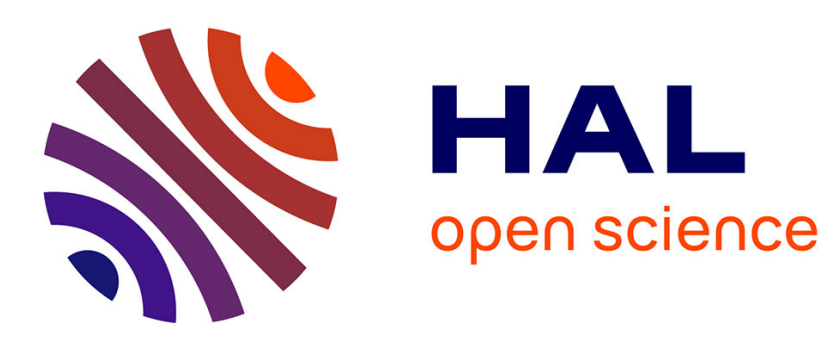

\title{
Spectroscopy and Photodissociation of the Perfluorooctanoate Anion
}

Suzie Douix, Héloïse Dossmann, Edith Nicol, Denis Duflot, Alexandre Giuliani

\section{To cite this version:}

Suzie Douix, Héloïse Dossmann, Edith Nicol, Denis Duflot, Alexandre Giuliani. Spectroscopy and Photodissociation of the Perfluorooctanoate Anion. Chemistry - A European Journal, 2018, 24 (58), pp.15572-15576. 10.1002/chem.201801997 . hal-01851786

\section{HAL Id: hal-01851786 https://hal.science/hal-01851786}

Submitted on 5 Nov 2018

HAL is a multi-disciplinary open access archive for the deposit and dissemination of scientific research documents, whether they are published or not. The documents may come from teaching and research institutions in France or abroad, or from public or private research centers.
L'archive ouverte pluridisciplinaire HAL, est destinée au dépôt et à la diffusion de documents scientifiques de niveau recherche, publiés ou non, émanant des établissements d'enseignement et de recherche français ou étrangers, des laboratoires publics ou privés. 


\section{Spectroscopy and Photodissociation of the Perfluorooctanoate Anion}

Suzie Douix,,$^{[a, b]}$ Héloïse Dossmann, ${ }^{[b]}$ Edith Nicol, ${ }^{[c]}$ Denis Duflot, ${ }^{[d]}$ and Alexandre Giuliani *[a,e]

[a] Synchrotron SOLEIL, l'Orme des Merisiers

Saint-Aubin BP48, 91192 Gif-sur-Yvette (France)

[b] Sorbonne Université, CNRS, Institut Parisien de Chimie Moléculaire

IPCM, 75005 Paris (France)

[c] Laboratoire de Chimie Moléculaire

Ecole polytechnique, CNRS, Université Paris-Saclay, 91128 Palaiseau France)

[d] Univ. Lille, UMR 8523-Physique des Lasers

Atomes et Molécules, 59000 Lille France)

[e] CEPIA, INRA, BP 71627, 44316 Nantes France)

E-mail: giuliani@synchrotron-soleil.fr

Supporting information and the ORCID identification number(s) for the author(s) of this article can be found under: https://doi.org/10.1002/chem.201801997.

DOI: 10.1002/chem.201801997

atmospheric chemistry

mass spectrometry

perfluoro compounds

photochemistry

UV/Vis spectroscopy 
Abstract: Perfluorocarbons, a class of fully fluorinated compounds, are highly persistent and toxic pollutants that are receiving increasing attention due to their widespread environmental distribution. In this study, attention was focused on one compound in particular, namely, perfluorooctanoic acid (PFOA). The first investigation of the UV/VUV photochemistry of the PFOA anion in the gas phase by action spectroscopy of selected ions is reported. Two main relaxation channels were identified: photodissociation and photodetachment. Absolute cross sections for the individual observed processes were measured. DFT calculations and natural transition orbital analysis were carried out to help in the interpretation of the experimental results.

\section{Introduction}

In recent years, perfluorocarbons (PFCs) have attracted the attention of the scientific community. ${ }^{[1,2]}$ They are a class of fully fluorinated compounds showing high thermal, biological, and chemical inertness. PFCs are widely used in surfactants, lubricants, paints, polishes, food packaging materials, and firefighting foams, and for the surface treatment of textiles, carpets, leather, and paper products. ${ }^{[3]}$ However, because of their C-F bonds, which have one of the highest bond energies, PFCs are extremely stable. Some of them are widely found in wildlife and water in the environment. Owing to their persistence, they can accumulate, and hence the question of their potential effect on natural ecosystems and living organisms arises. ${ }^{[4]}$ Their inherent stability also means that they may remain intact for a long time. When released into the atmosphere, they are among the most powerful greenhouse gases and have a global warming potential (GWP) between 7390 and 22800. ${ }^{[5]}$ GWPs are expressed as $\mathrm{CO}_{2}$ equivalents, calculated for a 100-year time period in compliance with the United Nations Framework Convention on Climate Change (UNFCCC) Guidelines. ${ }^{[6]}$ These compounds are therefore regulated under the Kyoto protocol. ${ }^{[7]}$ 
Photodissociation is an important atmospheric removal process for many ozonedepleting substances and halogenated degradation products. ${ }^{[8]} \mathrm{A}$ particular PFC, namely, perfluorooctanoic acid (PFOA, Figure 1), has attracted considerable attention from the scientific community. It is the final product of degradation of many of perfluorinated compounds. ${ }^{[9]}$ Because they are fully fluorinated, PFCs react weakly with the most prevalent atmospheric oxidants in the lower atmosphere (troposphere), such as $\mathrm{O}_{3}$ or the $\mathrm{HO}^{\circ}$ and $\mathrm{NO}_{3}{ }^{*}$ radicals. ${ }^{[7,8]}$ Hence, photolysis is most likely the primary loss process for PFCs in the atmosphere ${ }^{[7]} \mathrm{Up}$ to now, degradation of PFOA has been studied under UV/Vis irradiation alone ${ }^{[10,11,12]}$ or in combination with $\mathrm{H}_{2} \mathrm{O}_{2}$ or a tungstic heteropolyacid photocatalyst. ${ }^{[10]}$ All these studies aimed at developing techniques to remove stationary sources of PFOA. Moreover, gas phase spectroscopic studies are rather scarce in the literature. Absolute photoabsorption cross sections have indeed been only been reported for the hydrofluorocarbons. ${ }^{[13,14]}$ To the best of our knowledge, no data are available on absolute cross sections or on the photolysis of gas phase PFOA, certainly owing to its low volatility.

Action spectroscopy performed on gas phase mass- and charge-selected ions has recently attracted growing attention. ${ }^{[15,16]}$ This technique indeed profits from modern ionization techniques such as electrospray ionization to transfer large species into the gas phase in ionic form. These ions are then subjected to irradiation by a UV or X-ray photon beam for a certain amount of time. The product of irradiation is measured by mass spectrometry. This method is sensitive only to photoprocesses leading to a modification of the $\mathrm{m} / \mathrm{z}$ ratio of the precursor ion, and thus radiative decays cannot be observed. However, photodynamics occurring below the ionization threshold is accessible. Hence, in conjunction with synchrotron radiation, ion spectroscopy appears to be an appealing platform to access the spectroscopic and photodynamic properties of systems of low volatility over a wide photonenergy range.

Herein, we report measurements of absolute cross sections for photodetachment and photodissociation of the PFOA anion isolated in the gas phase in the 6-12 eV (206.6-103.3 
$\mathrm{nm})$ range. The main fragmentation channels were identified and the appearance energy measured. DFT calculations were carried out to help interpret the spectral features.

\section{Results and Discussion}

UV irradiation of the gas phase PFOA $[\mathrm{M}-\mathrm{H}]^{-}$anion leads to the formation of several fragment ions by photodissociation. The tandem mass spectrum obtained after irradiation with photons with $8 \mathrm{eV}(155 \mathrm{~nm})$ energy is shown in Figure 2.

Interestingly, this mass spectrum is very different from the MS/MS spectrum of the PFOA $[\mathrm{M}-\mathrm{H}]^{-}$ion under collision-induced dissociation (CID) conditions. Two main types of fragment ions are observed in Figure 2. The most abundant series $(m / z 331,281,231$, and 181) has the formula $\mathrm{C}_{n} \mathrm{~F}_{2 n-1}(n=4-7)$. To the best of our knowledge, such ions have not been reported under CID or any other activation conditions. Theoretical calculations suggest that these ions have most likely a cyclic structure that is more stable than any of the linear structures (see Supporting Information). Additional experiments showed that they could also be observed under the conditions of electron-detachment dissociation (see Supporting Information). In Figure 2, a second series of fragments, much less abundant, is constituted by the $m / z 269,219,169$, and 119 ions having the formula $\mathrm{C}_{n} \mathrm{~F}_{2 n+1}(n=2-5)$. These ions are the main fragments observed under classical MS/MS CID conditions. ${ }^{[17]}$ Moreover, the $[\mathrm{M}-\mathrm{H}-$ $\left.\mathrm{CO}_{2}\right]^{-}$ion does not show any dependence on the photon energy and is also observed without photons. Hence, this fragment is thermal in nature. This observation is at variance with a previous report, ${ }^{[11]}$ in which photodegradation of PFOA on $185 \mathrm{~nm}(6.7 \mathrm{eV})$ irradiation was proposed to proceed through photochemical decarboxylation.

The absolute photodissociation cross sections of the two series of fragment ions observed in Figure 2 are shown in Figure 3 in the 6-12 eV energy range. For the $\mathrm{C}_{n} \mathrm{~F}_{2 n-1}{ }^{-}$ family of ions, the appearance energy for the entire series was measured to be $7.6 \mathrm{eV}$ (Figure 3A). A broad spectral feature was observed for all ions, centered at $8.2 \mathrm{eV}$, after which the cross section decreases up to about $10 \mathrm{eV}$. The $\mathrm{C}_{7} \mathrm{~F}_{13}$ anion $(\mathrm{m} / \mathrm{z} 331)$ shows a specific 
spectral behavior above $10 \mathrm{eV}$, whereby its cross section increases and it shows a second broad band. Among the second series of fragments $\left(\mathrm{C}_{n} \mathrm{~F}_{2 n-1}{ }^{-}\right)$, a specific behavior is observed for the $m / z 169$ ion (Figure 3B), which exhibits a low-energy onset, below the $6.4 \mathrm{eV}$ limit of the present work. The cross section of the other fragments of the series starts increasing at 7.5 $\mathrm{eV}$ to reach a maximum at about $8 \mathrm{eV}$, similarly to the $\mathrm{C}_{n} \mathrm{~F}_{2 n-1}{ }^{-}$series. Summing up all the partial fragmentation cross sections produces the absolute total photodissociation cross section shown in Figure 3C.

Besides photodissociation, electron photodetachment may also take place on irradiation of the $[\mathrm{PFOA}-\mathrm{H}]^{-}$anion. ${ }^{[18]}$ The relative contributions of these two processes can be evaluated even if electron photodetachment of the $[\mathrm{PFOA}-\mathrm{H}]^{-}$anion produces a neutral molecule, which cannot be detected. In this case, the photodetachment contribution is derived from measurement of the depletion of the precursor ion. To this end, two mass spectra are recorded at each photon energy with the photons switched on or off. The intensity ratio of $[\mathrm{PFOA}-\mathrm{H}]^{-}$between these two measurements then gives access to the absolute photodetachment cross sections shown in Figure 3C. Comparison of the occurrences of the photodissociation and photodetachment processes shows that photodetachment by far dominates the photoinduced mechanisms, the cross section of which is indeed around 30 times larger than that for photodissociation. Such a difference in magnitude between dissociation and electron detachment in the VUV range has already been reported for oligosaccharides. ${ }^{[19]}$ Further, the photodetachment cross-section onset appears below $6.4 \mathrm{eV}$, that is, at lower energy than the photodissociation threshold.

Finally, combining both photodissociation and photodetachment cross sections gives a pseudo-absorption cross section for the PFOA anion in the gas phase, as shown in Figure 4. The gas phase spectrum in Figure 4 exhibits several bands of increasing intensity. Comparison of this spectrum with the corresponding photoabsorption cross section in solution shows good agreement in the small overlapping region. The onset of the solution data is found at about $5.5 \mathrm{eV}(225 \mathrm{~nm})$, which is consistent with the previous solution absorption 
measurements of Hori et al. ${ }^{[10]}$ and Chen et al. ${ }^{[11]}$ Time-dependent DFT (TDDFT) calculations at the M06-2X/aug-cc-pVDZ level of theory were performed to get some insight into the nature of the electronic transitions. The theoretical results are compared to the experimental data in Figure 4. The most notable feature is the very large number of transitions involved in the photoabsorption process. The position of the lowest-energy feature of the absorption spectrum is reproduced within $0.5 \mathrm{eV}$ by the calculation. To get deeper insight into the nature of the involved transitions, a natural transition orbitals (NTO) analysis $^{[20]}$ was performed for the most-intense transitions (see Table S5 in the Supporting Information) and the selection presented in Figure 5). It appears that, up to $6.5 \mathrm{eV}$, most of the excited states exhibit features of Rydberg states. For instance, transition 11 clearly produces an s Rydberg excited state (with pronounced charge-transfer nature), whereas transition 35 , predicted at $5.48 \mathrm{eV}$, is more akin to a p-type orbital. From Table S5 (Supporting Information) it emerges that the situation changes at transition 71, at which the excited states now have valence or mixed Rydberg/valence characters (e.g., transition 91, Figure 5). This result accounts for the striking observation of a large photodetachment in the low-energy range $(<7.5 \mathrm{eV})$, where photodissociation channels are not observed, as shown in Figure 3. Photodetachment occurs in a two-step process, as proposed by Dugourd, Antoine and co-workers, ${ }^{[16]}$ in which photoabsorption produces a localized excited state, which may undergo detachment of an electron if the energy of the state is above the sum of the electron binding energy and the repulsive Coulombic barrier. The adiabatic detachment energy (ADE) of the methylcarboxylate anion has been reported to be $3.25 \mathrm{eV}$ by Wang et al. ${ }^{[21]}$ Although perfluorination might affect this value, the ADE value of the PFOA anion is unlikely to change by several electron volts. Hence, the low-energy Rydberg states are all above the detachment threshold and thus are susceptible to electron photodetachment.

Above $7.5 \mathrm{eV}$, the photodissociation cross section increases strongly (Figure 3 ). The NTO analysis shows that from about $6.5 \mathrm{eV}$, transitions with notable oscillator strength and marked valence character appear, such as transition 71 (see Figure 5). For transition 71, the 
unoccupied natural orbital is delocalized over the backbone and has antibonding character along the $\mathrm{C}_{\alpha}-\mathrm{C}_{\text {carbonyl }}$ and $\mathrm{C}-\mathrm{F}$ bonds. These results are in line with the observation of enhanced fragmentation yields at higher photon energy. Moreover, the delocalized nature of the unoccupied orbital does not favor particular bond breaking and is consistent with the partial photodissociation cross sections shown in Figures 1 and A and B, in which fragmentation occurs over the entire background. Some transitions, such as transition 91, which has mixed valence/Rydberg character, as observed in Figure $3 \mathrm{C}$, may contribute to both electron detachment and fragmentation channels.

Chen et al. ${ }^{[11]}$ observed that $185 \mathrm{~nm}$ irradiation in water leads to degradation of PFOA into smaller chains and to defluorination. ${ }^{[10]}$ The proposed mechanism involved decarboxylation of PFOA to form a $\mathrm{C}_{7} \mathrm{~F}_{15}{ }^{\circ}$ intermediate. This radical would then react with water to produce $\mathrm{C}_{6} \mathrm{~F}_{13} \mathrm{COOH}$ and two fluoride ions. Shorter chains are generated by repeating this process. Recently, Liu and co-workers corroborated the first decarboxylation step proposed by Chen for irradiation of PFOA in water. ${ }^{[11]}$ However, the defluorination channels suggested by Chen et al. ${ }^{[11]}$ are not observed here. Furthermore, the $\mathrm{C}_{n} \mathrm{~F}_{2 n+1^{-}}$ intermediate proposed by previous workers is directly observed in the present experiment as a photochemical product without involving sequential degradation reactions. However, the $\mathrm{C}_{n} \mathrm{~F}_{2 n+1}{ }^{-}$ion series is of much lower abundance than the cyclic $\mathrm{C}_{n} \mathrm{~F}_{2 n-1}{ }^{-}$family. The latter are the most abundant photofragments produced on VUV irradiation (above $7.5 \mathrm{eV}, 165.3 \mathrm{~nm}$ ) of the gas phase PFOA anion. The $\mathrm{C}_{n} \mathrm{~F}_{2 n-1}{ }^{-}$ions were found to be very stable, and Bera et al. ${ }^{[22]}$ have shown that these compounds have considerable IR absorption in the atmospheric window (ca. 800-1200 $\mathrm{cm}^{-1}$ ) and thus a high GWP.

\section{Conclusion}

We have reported the first investigation on the UV/VUV photochemistry of the PFOA anion in the gas phase by action spectroscopy. Two main relaxation channels were identified: photodissociation and photodetachment. Absolute cross sections for all individual processes observed were measured. It appears that photodetachment dominates over all other relaxation 
channels. Using an NTO analysis, we could establish that the low-energy excited states may be described as Rydberg states, which account for the observed abundant electron detachment and low-abundance dissociation at low energy. At higher energy, the NTO analysis indicates that valence excited states are populated, which correlates well with the opening of dissociation channels. We have reported a new fragmentation route to cyclic perfluoroalkyl anions that has never been described so far. The PFOA anion indeed photodissociates mostly into $\mathrm{C}_{n} \mathrm{~F}_{2 n-1}{ }^{-}$fragment ions, which have a stable and cyclic structures. Hence, photodegradation of PFOA releases cyclic perfluorocarbon anions, which in turn exhibit notable GWP. ${ }^{[22]}$

\section{Experimental Section}

\section{Chemicals}

Perfluorooctanoic acid $\left(\mathrm{C}_{7} \mathrm{~F}_{15} \mathrm{COOH}\right.$, PFOA, $\left.98 \%\right)$ was purchased from Wellington Laboratories and used without further purification. $10 \mu \mathrm{M}$ solutions were prepared in $70(80 / 20$ methanol/acetonitrile)/30 (water) (v/v) with $10 \mathrm{mM}$ ammonium acetate buffer.

\section{Spectrophotometry}

UV absorption measurements on an aqueous PFOA solution $\left(50 \mathrm{mg} \mathrm{L}^{-1}\right)$ were performed with an Analytik Jena spector 210, UV/Vis spectrophotometer, from 210 to $280 \mathrm{~nm}$ with a $1 \mathrm{~cm}$ cell.

\section{Ion spectroscopy}

VUV action spectroscopy was performed with a commercial linear ion-trap mass spectrometer (LTQ, Thermo Fisher Scientific, San Jose, USA) coupled to the DESIRS VUV beamline ${ }^{[23]}$ of the French SOLEIL synchrotron radiation facility. ${ }^{[24]}$ This experimental setup is briefly described in the Supporting Information. PFOA solution was directly introduced into the experiment by an electrospray ion source at a flow rate of $5 \mu \mathrm{L} \mathrm{min}^{-1}$ in negative-ion mode. The trapped precursor ions were then irradiated with VUV photons. A mass spectrum was recorded at each given wavelength. Provided that the geometries of the photon beam and the ion precursor packet are known, it is possible 
to obtain the cross sections as absolute values according to the procedure described in the Supporting Information. $^{[25]}$

\section{Theoretical calculations}

Geometry optimizations, frequency, and single-point energy calculations were performed with the Gaussian 09 package ${ }^{[26]}$ by using the Truhlar M06-2X functional ${ }^{[27]}$ coupled to the diffuse augmented Dunning correlation consistent basis set aug-cc-pVDZ. ${ }^{[28,29]}$ The photoabsorption spectrum was calculated by TDDFT with the same functional and extension of the basis set with $5 \mathrm{~s} 5 \mathrm{p} 2 \mathrm{~d}$ diffuse orbitals at the center of mass of the molecule for a better description of Rydberg states. ${ }^{[30]}$ Oscillator strengths were obtained in the length gauge.

\section{Acknowledgements}

The SOLEIL synchrotron radiation facility is acknowledged for providing beamtime and technical support. Laurent Nahon is highly acknowledged for constant support. This work was performed using HPC resources from GENCI-TGCC (Grant 2018-A0010806820), from the HPCaVe centre at UPMC-Sorbonne Université and from the Centre de Ressources Informatiques (CRI) of the Université of Lille. S.D. is grateful to the Ile-de-France region through DIM Analytics for supporting her PhD funding. This work was partially supported by the Agence Nationale de la Recherche Scientifique, France, under project number ANR-08BLAN-0065. D.D. acknowledges support from the CaPPA project (Chemical and Physical Properties of the Atmosphere), funded by the French National Research Agency (ANR) through the PIA (Programme d'Investissement d'Avenir) under Contract No. ANR-10LABX-005 and is a contribution to the CPER research project CLIMIBIO. D.D. also thanks the French Ministère de l'Enseignement Supérieur et de la Recherche, the Hauts de France Region and the European Funds for Regional Economical Development for their financial support to this project. Financial support from the National FT-ICR network (FR 3624 CNRS) for conducting the research is gratefully acknowledged.

\section{Conflict of interest}


The authors declare no conflict of interest.

\section{References}

1. P. De Voogt, M. Sáez, TrAC-Trends Anal. Chem. 2006, 25, 326-342.

2. J. P. Giesy, K. Kannan, Environ. Sci. Technol. 2002, 36, 146A-152A.

3. J. De Boer, P. Garrigues, J.-D. Gu, K. C. Jones, T. P. Knepper, A. Newton, D. L. Sparks, n.d.

4. I. Langlois, M. Oehme, Rapid Commun. Mass Spectrom. 2006, 20, 844-850.

5. National Institute for Public Health and the Environment, 2017, 364.

6. D. J. Ivy, T. Arnold, C. M. Harth, L. P. Steele, J. Uhle, M. Rigby, P. K. Salameh, M. Leist, P. B. Krummel, P. J. Fraser, Atmos. Chem. Phys. 2012, 12, 4313-4325.

7. J. B. Burkholder, R. A. Cox, A. R. Ravishankara, Chem. Rev. 2015, 115, 3704-3759.

8. K. Prevedouros, I. T. Cousins, R. C. Buck, S. H. Korzeniowski, Environ. Sci. Technol. 2006, $40,32-44$.

9. I. Stemmler, G. Lammel, Atmos. Chem. Phys. 2010, 10, 9965-9980.

10. H. Hori, E. Hayakawa, H. Einaga, S. Kutsuna, K. Koike, T. Ibusuki, H. Kiatagawa, R. Arakawa, Environ. Sci. Technol. 2004, 38, 6118-6124.

11. J. Chen, P. y. Zhang, J. Liu, J. Environ. Sci. 2007, 19, 387-390.

12. R. R. Giri, H. Ozaki, T. Morigaki, S. Taniguchi, R. Takanami, Water Sci. Technol. 2011, 63, 276-282.

13. J. J. Orlando, B. Burkholder, A. Mckeen, A. R. P. Avishankara, J. Geophys. Res.,1991, 96(D3), 5013-5023.

14. G. D. Lonardo, G. Masciarelli, J. Quant. Spectrosc. Radiat. Transfer 2000, 66, 129-142. 
15. A. Giuliani, A. R. Milosavljević, F. Canon, L. Nahon, Mass Spectrom. Rev. 2014, 33, 424-441.

16. R. Antoine, P. Dugourd, Phys. Chem. Chem. Phys. 2011, 13, 16494-16509.

17. G. Arsenault, A. McAlees, R. McCrindle, N. Riddell, Rapid Commun. Mass Spectrom. 2007, 21, 3803-3814

18. J. Simons, J. Phys. Chem. A 2008, 112, 6401-6511.

19. Q. Enjalbert, C. Brunet, A. Vernier, A. R. Allouche, R. Antoine, P. Dugourd, J. Lemoine, A. Giuliani, L. Nahon, J. Am. Soc. Mass Spectrom. 2013, 24, 1271-1279.

20. R. L. Martin, J. Chem. Phys. 2003, 118, 4775-4777.

21. X.-B. Wang, H.-K. Woo, L.-S. Wang, B. Minofar, P. Jungwirth, J. Phys. Chem. A 2006, $110,5047-5050$.

22. P. P. Bera, L. Horný, H. F. Schaefer, J. Am. Chem. Soc. 2004, 126, 6692-6702.

23. L. Nahon, N. De Oliveira, G. A. Garcia, J. F. Gil, B. Pilette, O. Marcouillé, B. Lagarde, F. Polack, J. Synchrotron Radiat. 2012, 19, 508-520.

24. A. R. Milosavljević, C. Nicolas, J. F. J.-F. Gil, F. Canon, M. Réfrégiers, L. Nahon, A. Giuliani, J. Synchrotron Radiat. 2012, 19, 174-178.

25. S. Douix, D. Duflot, D. Cubaynes, J.-M. J.-M. Bizau, A. Giuliani, J. Phys. Chem. Lett. 2017, 8, 7-12.

26. M. J. Frisch, G. W. Trucks, H. B. Schlegel, G. E. Scuseria, M. A. Robb, J. R. Cheeseman, G. Scalmani, V. Barone, B. Mennucci, G. A. Petersson, H. Nakatsuji, M. Caricato, X. Li, H. P. Hratchian, A. F. Izmaylov, J. Bloino, G. Zheng, J. L. Sonnenberg, M. Hada, M. Ehara, K. Toyota, R. Fukuda, J. Hasegawa, M. Ishida, T. Nakajima, Y. Honda, O. Kitao, H. Nakai, T. Vreven, J. A. Montgomery, Jr., J. E. Peralta, F. Ogliaro, M. Bearpark, J. J. Heyd, E. Brothers, K. N. Kudin, V. N. Staroverov, R. Kobayashi, J. Normand, K. Raghavachari, A. Rendell, J. C. Burant, S. S. Iyengar, J. Tomasi, M. Cossi, N. Rega, J. M. Millam, M. Klene, J. E. Knox, J. B. Cross, V. Bakken, C. Adamo, J. Jaramillo, R. Gomperts, R. E. Stratmann, O. Yazyev, A. J. Austin, R. Cammi, C. Pomelli, J. W. Ochterski, R. L. Martin, K. Morokuma, V. G. Zakrzewski, G. A. Voth, P. Salvador, J. J. Dannenberg, S. Dapprich, A. D. Daniels, Ö. Farkas, J. B. Foresman, J. V. Ortiz, J. Cioslowski, D. J. Fox, Gaussian 09 (Gaussian, Inc., Wallingford CT, 2009). 
27. Y. Zhao, D. G. Truhlar, Theor. Chem. Acc. 2008, 120, 215-241.

28. T. H. Dunning, J. Chem. Phys. 1989, 1007, 90.

29. R. A. Kendall, T. H. Dunning, R. J. Harrison, R. J. Harrison, J. Chem. Phys. 1992, 6796, 96 .

30. K. Kaufmann, W. Baumeister, J. M, J. Phys. B 1989, 22, 2223.

Manuscript received: April 21, 2018

Revised manuscript received: July 3, 2018

Accepted manuscript online: July 4, 2018 
Figure
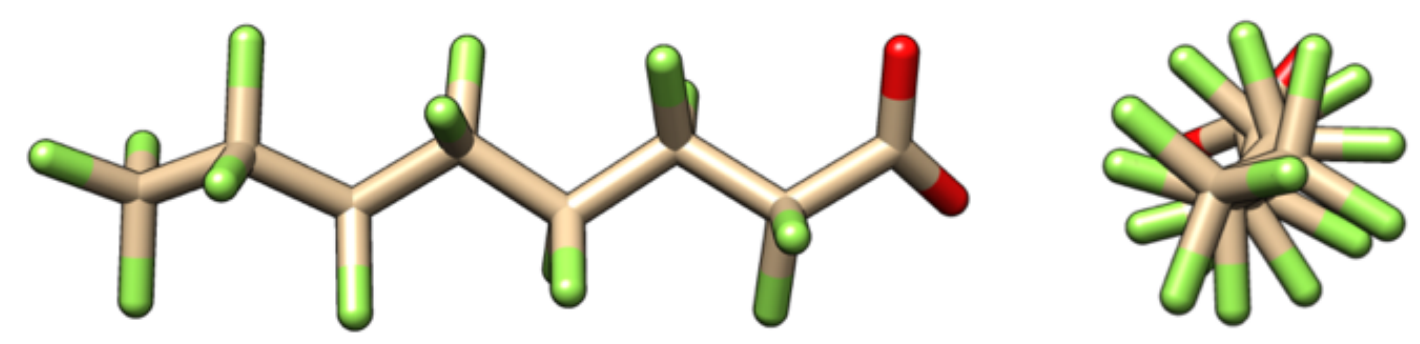

Figure 1. Structure of the PFOA anion calculated at the M06-2X/aug-cc-pVDZ level of theory.

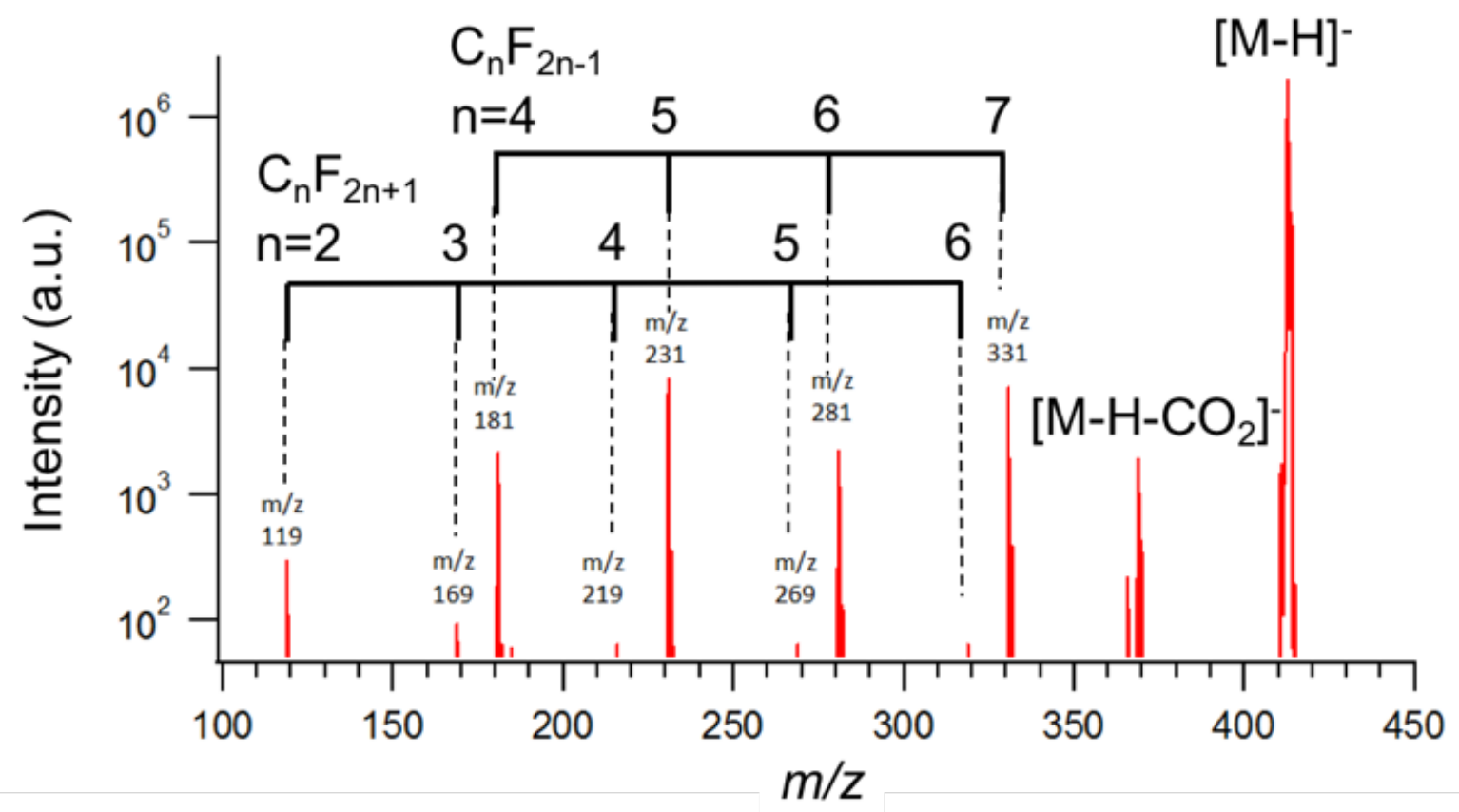

Figure 2. Mass spectrum of the selected $[\mathrm{PFOA}-\mathrm{H}]^{\mathrm{M}-}$ ion after activation at $8 \mathrm{eV}(155$ $\mathrm{nm})$. 

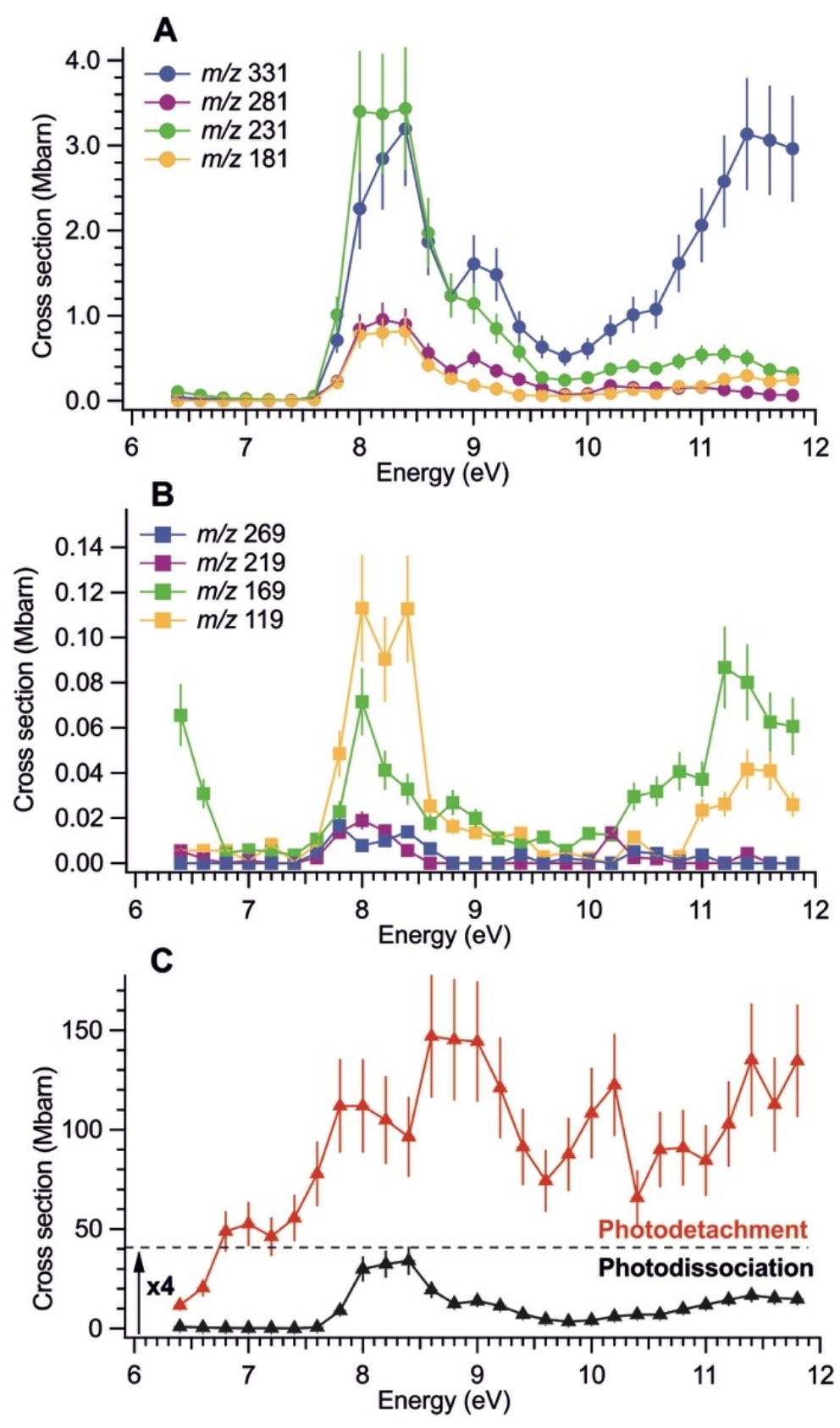

Figure 3. Absolute photodissociation cross sections in the $6.4-12.0 \mathrm{eV}$ energy range for A) the $\mathrm{C}_{n} \mathrm{~F}_{2 n-1}{ }^{-}$and B) the $\mathrm{C}_{n} \mathrm{~F}_{2 n+1}{ }^{-}$fragments. C) Absolute total photodissociation and photodetachment cross sections in the same energy range. For the sake of clarity, the photodissociation cross section (black curve, C) has been multiplied by a factor 4 . 


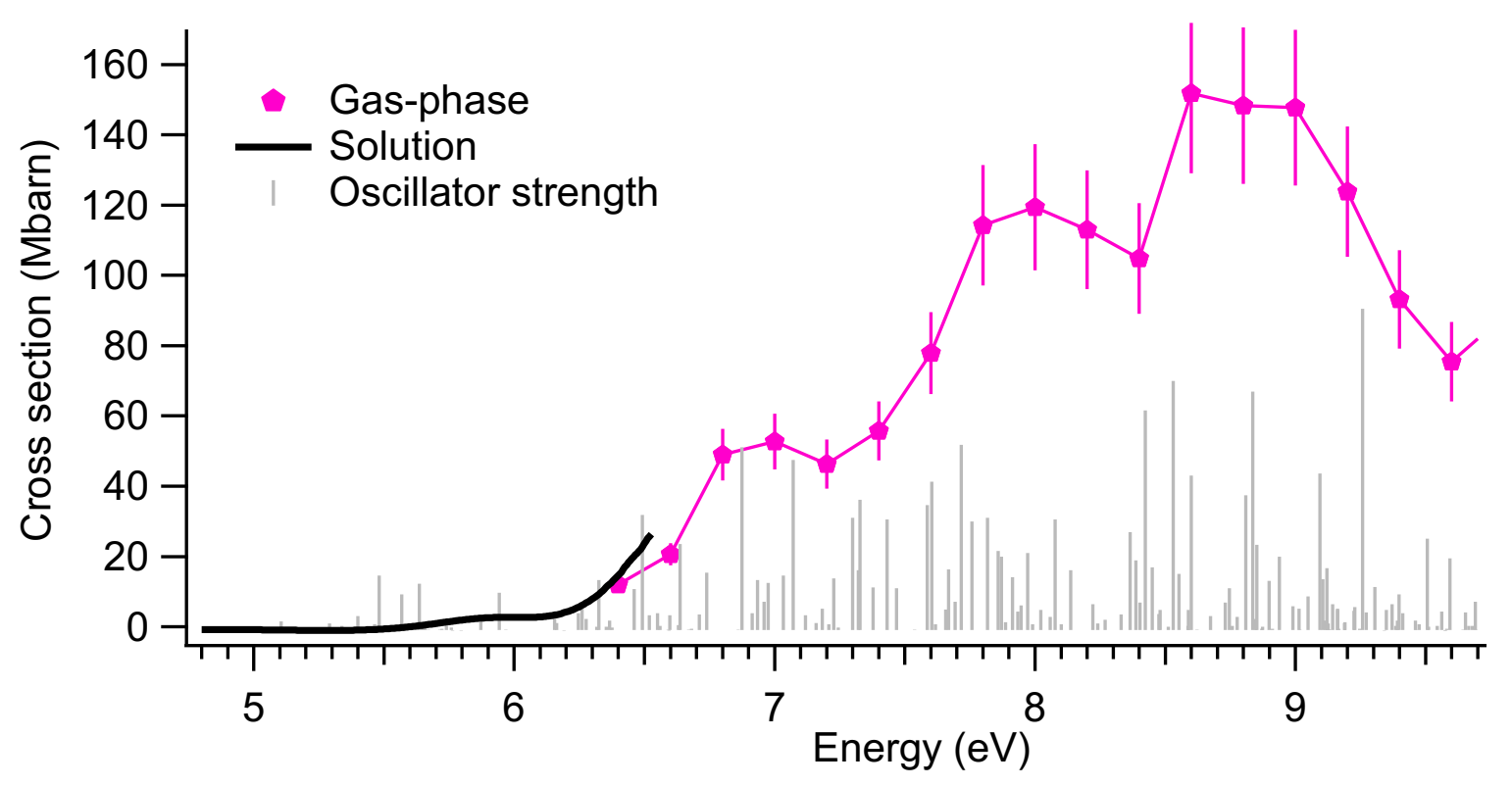

Figure 4. Comparison of the pseudo-absorption gas phase spectrum (pink curve) measured in the 6.4-9.7 eV energy range with the solution phase photoabsorption cross section data (black curve) of the PFOA anion recorded in the 4.8-6.8 eV energy range. Gray sticks represent the oscillator strengths of the simulated spectrum (TDDFT calculations). 

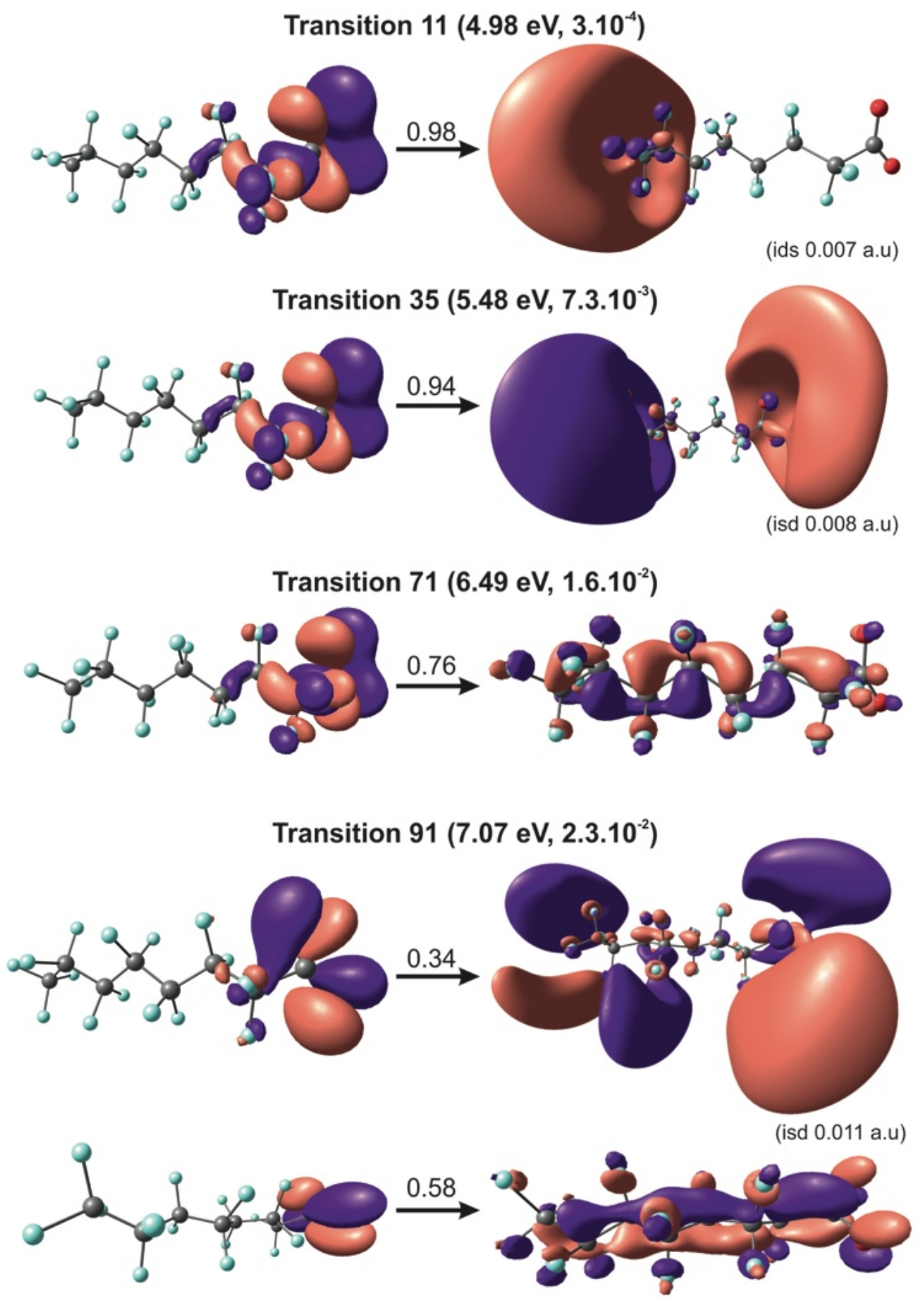

Figure 5. Natural transition orbitals for some characteristic transitions. For each transition, the excitation energy and the corresponding oscillator strengths are indicated in parentheses and the associated weights above the arrows. If not stated otherwise, the isodensity surface is at 0.03 e $\AA^{-3}$. 


\title{
Spectroscopy and photodissociation of perfluorooctanoic acid (PFOA) anion
}

\author{
Suzie Douix ${ }^{[a, b]}$, Héloïse Dossmann ${ }^{[b]}$, Edith Nicol ${ }^{[c]}$, Denis Duflot ${ }^{[\mathrm{d}, \mathrm{e}]}$, and Alexandre \\ Giuliani*[a,f]
}
[a] Synchrotron SOLEIL, I'Orme des Merisiers, Saint-Aubin BP48, 91192 Gif-sur-Yvette, France
[b] Sorbonne Université, CNRS, Institut Parisien de Chimie Moléculaire, IPCM, 75005 Paris
[c] Laboratoire de Chimie Moléculaire, Ecole polytechnique, CNRS, Université Paris-Saclay, 91128 Palaiseau, France
[d] CNRS, UMR 8523, F-59000 Lille, France
[e] Université Lille, UMR 8523 - Physique des Lasers, Atomes et Molécules, F-59000 Lille, France
[f] CEPIA, INRA, BP 71627, FR-44316 Nantes, France

Corresponding Author:

*E-mail: giuliani@synchrotron-soleil.fr

\section{Content}

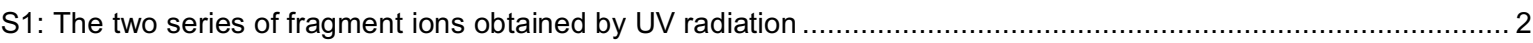

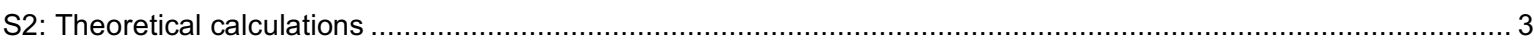

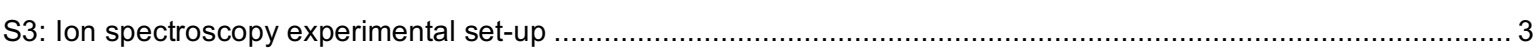

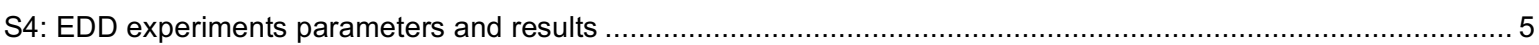




\section{S1: The two series of fragment ions obtained by UV radiation}

Two series of fragments ions were observed. A first series is constituted with the $\mathrm{m} / \mathrm{z} 119,169,219,269$ and 369 ions, having the $\mathrm{C}_{n} \mathrm{~F}_{2 n+1}{ }^{-}$formula $(\mathrm{n}=2-7)$, and a second one with $\mathrm{m} / \mathrm{z} 181,231,281$ and 331 ions, which follow the $\mathrm{C}_{n} \mathrm{~F}_{2 n-1}$ formula $(n=4-7$.) Table S1 summarizes the developed formula for all these ions.

Table S1: Mass to charge ratio and developed formula for the $C_{n} F_{2 n+1}$ and $C_{n} F_{2 n-1}$ fragment ion series

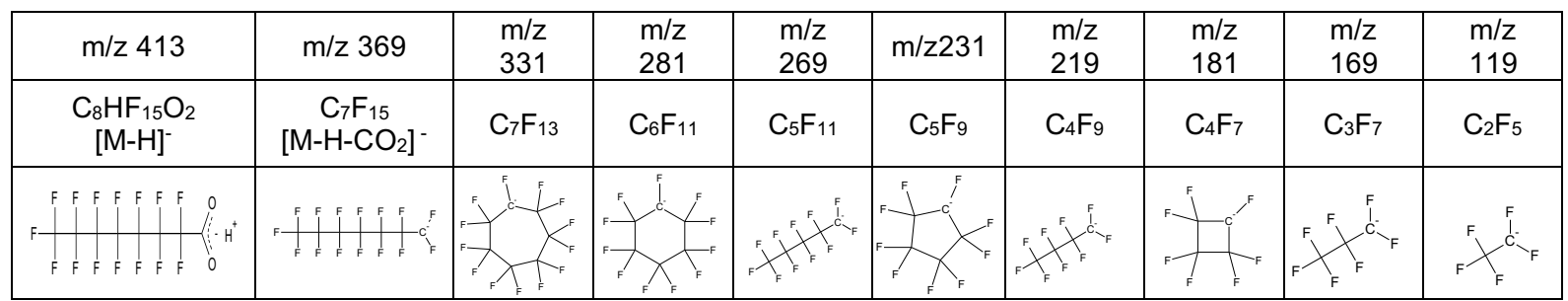




\section{S2: Theoretical calculations}

Table S2: Calculated electronic and zero-point energies of the main photodissociation $\mathrm{C}_{n} \mathrm{~F}_{2 n-1}{ }^{-}$fragments of [PFOA-H] obtained at the M06-2X/aug-cc-pVDZ level of theory. For each fragment, the most stable cyclic and linear structures are presented and their relative energies are given.

\begin{tabular}{|c|c|c|c|}
\hline & $\mathrm{E}_{\mathrm{el}}(\mathrm{H})$ & ZPE (H) & $E_{\text {rel }}(\mathrm{eV})$ \\
\hline F331 сyс $^{-}$ & -1564.43824 & 0.0806642 & 0.0 \\
\hline F331 lin $^{-}$ & -1564.400717 & 0.0780611 & 0.95 \\
\hline F281 $_{\text {сyc }}{ }^{-}$ & -1326.707536 & 0.0679985 & 0.0 \\
\hline F281 lin $^{-}$ & -1326.652357 & 0.065619 & 1.44 \\
\hline${\text { F231 } \text { сyс }^{-}}^{-}$ & -1088.95202 & 0.0550282 & 0.0 \\
\hline F231 lin $^{-}$ & -1088.903143 & 0.0529504 & 1.27 \\
\hline F181 $_{\text {сyc }}{ }^{-}$ & -851.1722846 & 0.0413797 & 0.0 \\
\hline F181 lin $^{-}$ & -851.1488474 & 0.0404362 & 0.61 \\
\hline
\end{tabular}

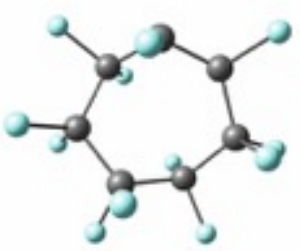

F331 $1_{\text {eye }}$

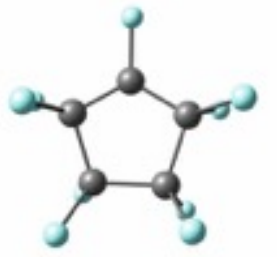

F231 eye

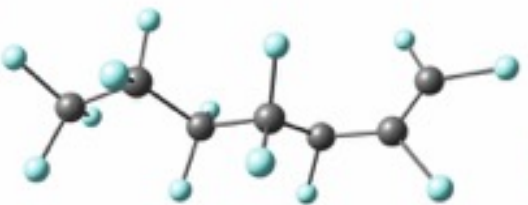

F331

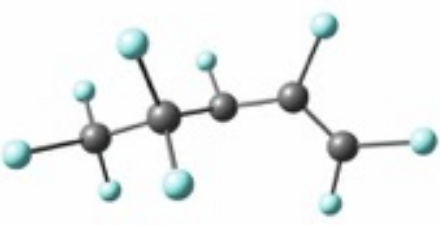

$\mathrm{F}^{231_{\text {lin }}}$

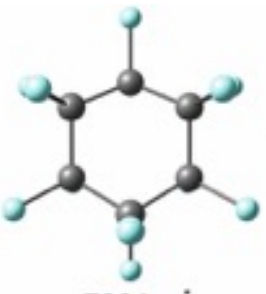

F281

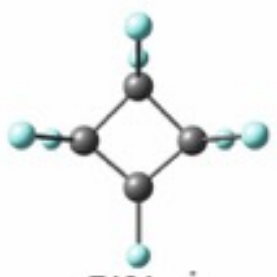

F181

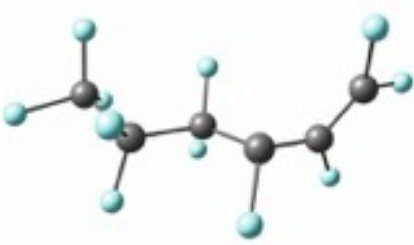

F281 iin

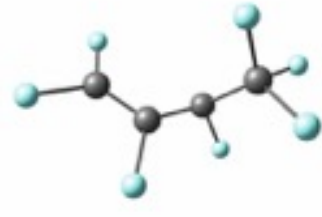

$\mathrm{F} 181_{\text {lin }}$

Figure S1: Cyclic and linear structures of the most stable $\mathrm{C}_{n} \mathrm{~F}_{2 \mathrm{n}-1^{-}}$fragments. 


\section{S3: Ion spectroscopy experimental set-up}

We used a commercial linear ion-trap mass spectrometer (LTQ, Thermo Fisher Scientific, San Jose, USA) coupled to the DESIRS [1] VUV beamline of the SOLEIL synchrotron radiation facility (France) to perform action spectroscopy in the VUV range [2]. A schematic drawing of the experimental assembly is given in Figure 1.

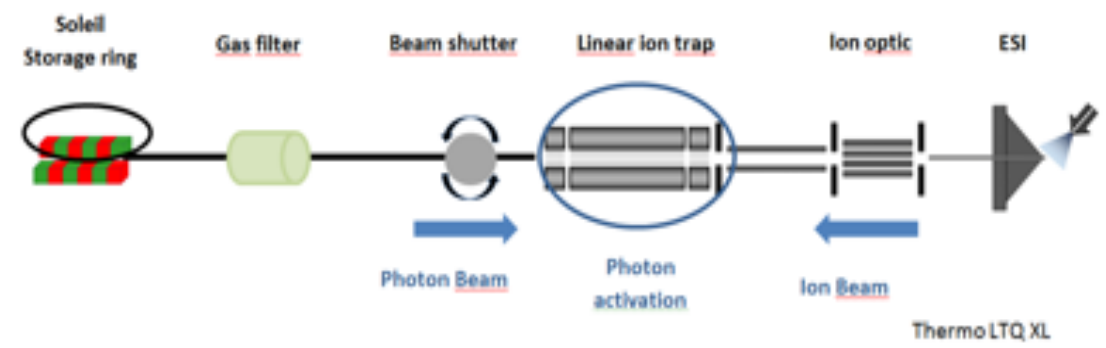

Figure S2: Experimental setup based upon a linear ion-trap mass spectrometer coupled with the DESIRS beamline of the synchrotron radiation facility.

The experimental procedure consists of the following steps. First, precursor ions formed by an electrospray source (ESI) are injected into the linear ion trap through the ion optic. The $\mathrm{m} / \mathrm{z}$ of interest are then selected and stored into the ion trap. When the desire ion capacity is reached, the beam shutter opens and starts the irradiation of the precursor ions. After the desired irradiation time, the beam shutter closes and a mass spectrum is recorded. The monochromator and undulator position move to the next energy, and the procedure is repeated. To obtain a good signal-to-noise ratio, a high photon flux and optimal overlap between the trapped ion packet and the incident photon are crucial. Gas filters were used to ensure spectral purity.

Experiments have been conducted by irradiation of the trapped precursor ions. At every given wavelength, a mass spectrum has been recorded. Providing that the geometries of the photon beam and the ion precursor packet are known, it is possible to obtain the cross sections in absolute value according to the following equation derived from the kinetic equations [3].

$$
\sigma=\frac{1}{t . \Phi} \ln \left(1+\frac{S_{t} \cdot \varepsilon_{s}}{P_{t} \cdot \varepsilon_{p}}\right)=\frac{1}{t . \Phi} \ln \left(1+\% S_{t} \frac{\varepsilon_{s}}{\varepsilon_{p}}\right)
$$

Equation 1: Determination of the absolute cross section for a first order chemical reaction photochemical process Here, \%St is the percentage of product ion $\mathrm{S}$ produced by photoionization of the precursor ion $\mathrm{P}, \mathrm{t}$ is the irradiation time, $\Phi$ is the absolute photon flux normalized by the area of the photon beam $\left(\mathrm{ph} . \mathrm{s}^{-1} \cdot \mathrm{cm}^{-2}\right)$ and $\varepsilon s / \varepsilon p$ is the ratio of the ion detection efficiency. For this latter term, we used data provided by Thermo Fischer Scientific.

For the photon flux measurements a calibrated photodiode (AXUV100, International Radiation Detectors) was used and placed just before the entrance of the ions trap. The photon flux was measured in the $10^{11}-10^{12} \mathrm{ph} . \mathrm{s}^{-1}$ range.

L. Nahon, N. De Oliveira, G. A. Garcia, J. F. Gil, B. Pilette, O. Marcouillé, B. Lagarde, and F. Polack, "DESIRS: A state-of-the-art VUV beamline featuring high resolution and variable polarization for spectroscopy and dichroism at SOLEIL," J. Synchrotron Radiat., vol. 19, no. 4, pp. 508-520, 2012. activation technique for tandem mass spectrometry," J. Synchrotron Radiat., vol. 19, no. 2, pp. 174-178, Mar. 2012.

[3] S. Douix, D. Duflot, D. Cubaynes, J.-M. Bizau, and A. Giuliani, "Photoionization of the Buckminsterfullerene Cation," J. Phys. Chem. Lett., pp. 7-12, 2016. 


\section{S4: EDD Experimental Parameters and Results}

Electron detachment dissociation (EDD) experiments have been conducted on a Bruker SolariX XR 9.4 Tesla instrument equipped with a CombiSource 1.0 source located at the Ecole Polytechnique in Palaiseau. During this electron-based approach, the precursor ion is bombarded by electrons which kinetic energy is superior to $10 \mathrm{eV}$. This process leads to the detachment of an electron or to a fragmentation phenomenon.

By EDD experiments on the PFOA anions, it is not possible to detect the phenomenon of electron detachment because of the formation of a neutral molecule; only the fragmentation phenomenon is observable.

PFOA solutions have been prepared with the same procedure as for the ion spectroscopy experiments and introduce via direct infusion.

The following EDD parameters have been used: an ECD pulse length of 20s, an ECD bias of $30 \mathrm{~V}$ and an ECD Lens of 10 V. 500 scans were accumulated and led to the activated mass spectrum shown in figure 2.

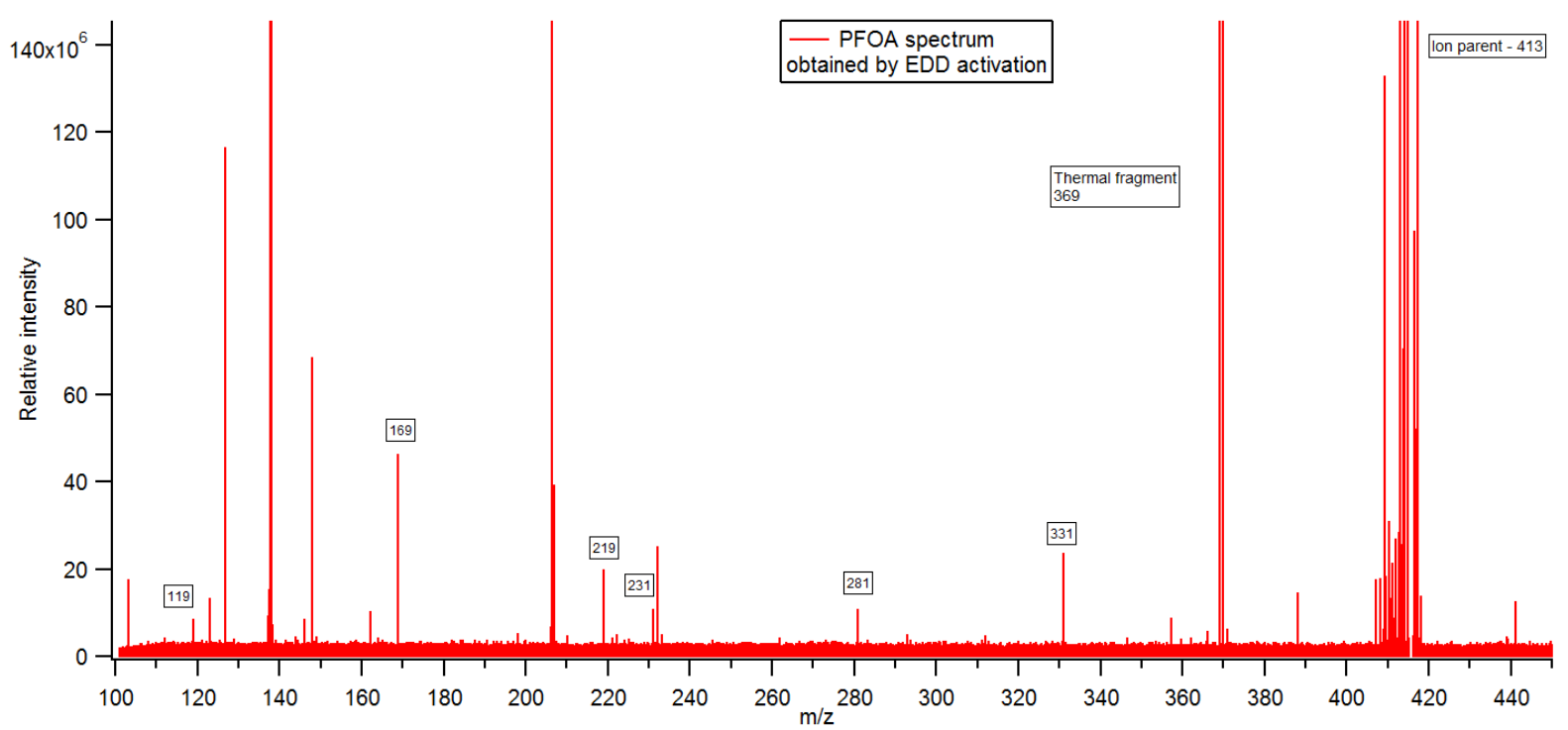

Figure S3: EDD-activated MS of mass-selected [PFOA-H]' (500 scans accumulation).

EDD activation leads to the observation of different ions were observed: the linear ions, $\mathrm{m} / \mathrm{z} 119,169,219$ and 369 ,, as well as the cyclic ions, $\mathrm{m} / \mathrm{z} 231,281$ and 331. 


\section{S5: Natural Transition Orbital (NTO)}

To obtain a qualitative description of electronic excitation, NTO have been considered for the main TDDFT transitions.

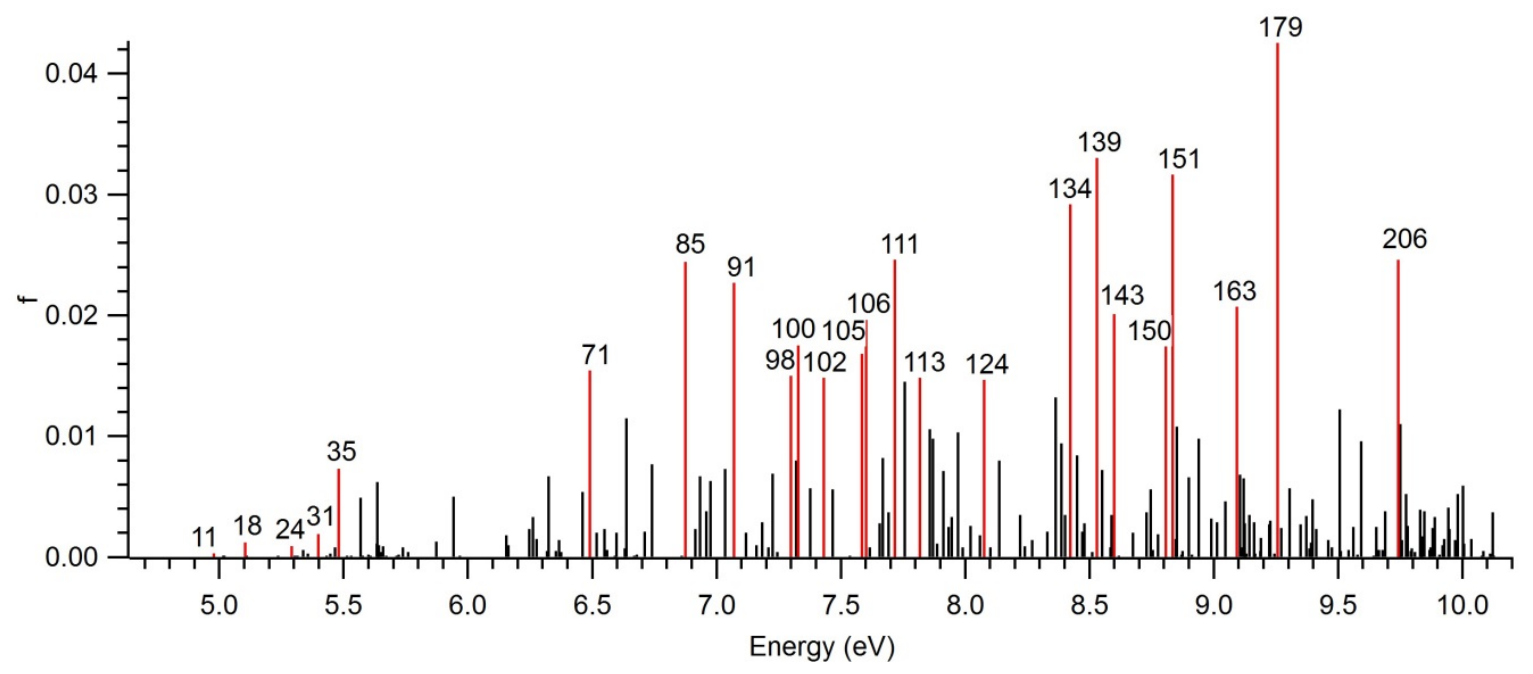

Figure S4: Simulated UV/vis spectrum obtained by TD-DFT calculations. Sticks represent electronic excitation. In red are the transitions for which the NTOs have been considered. The number of the transition is indicated above the stick. 

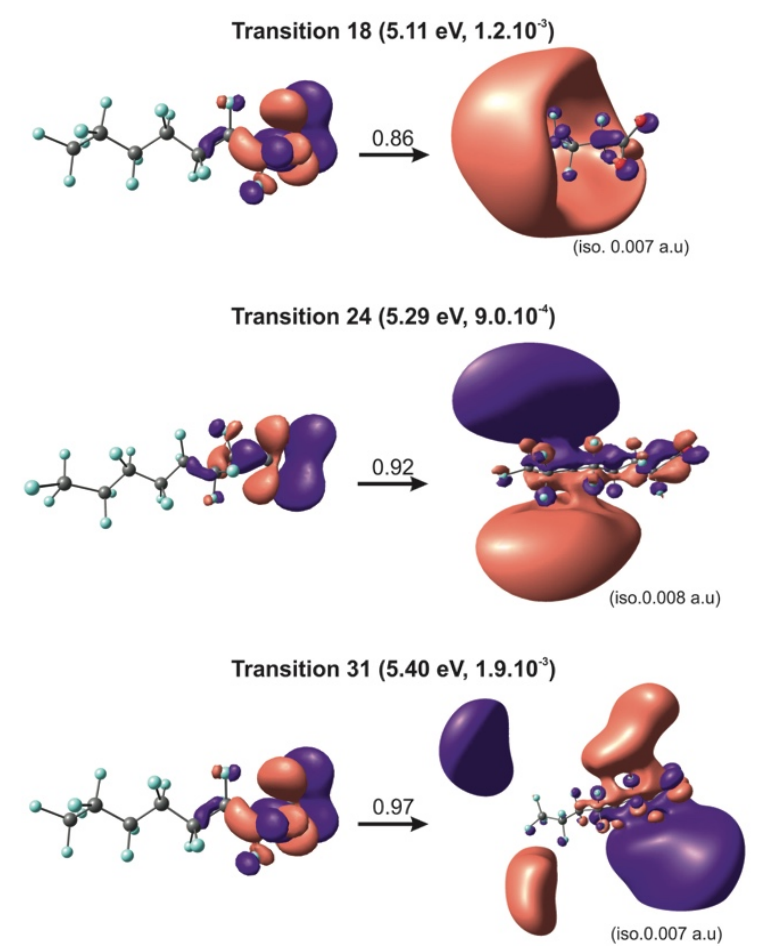

Transition $85\left(6.87 \mathrm{eV}, 2.4 .10^{-2}\right)$
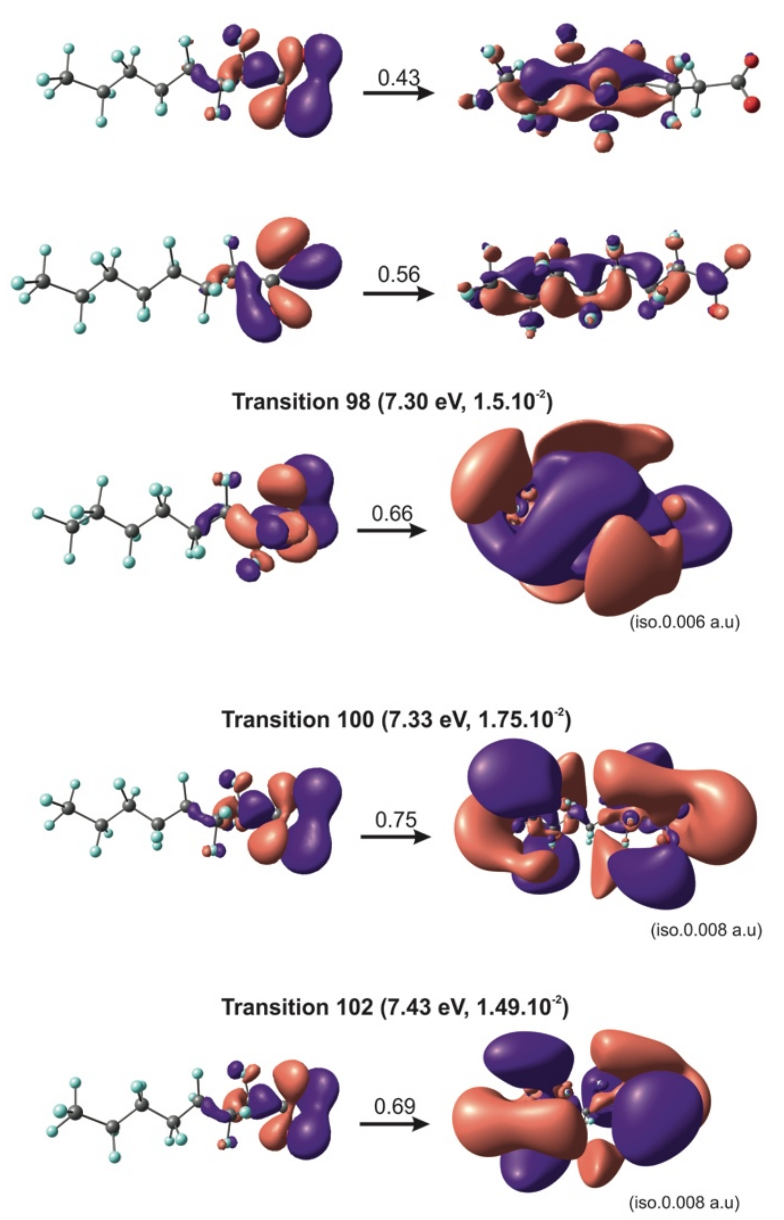
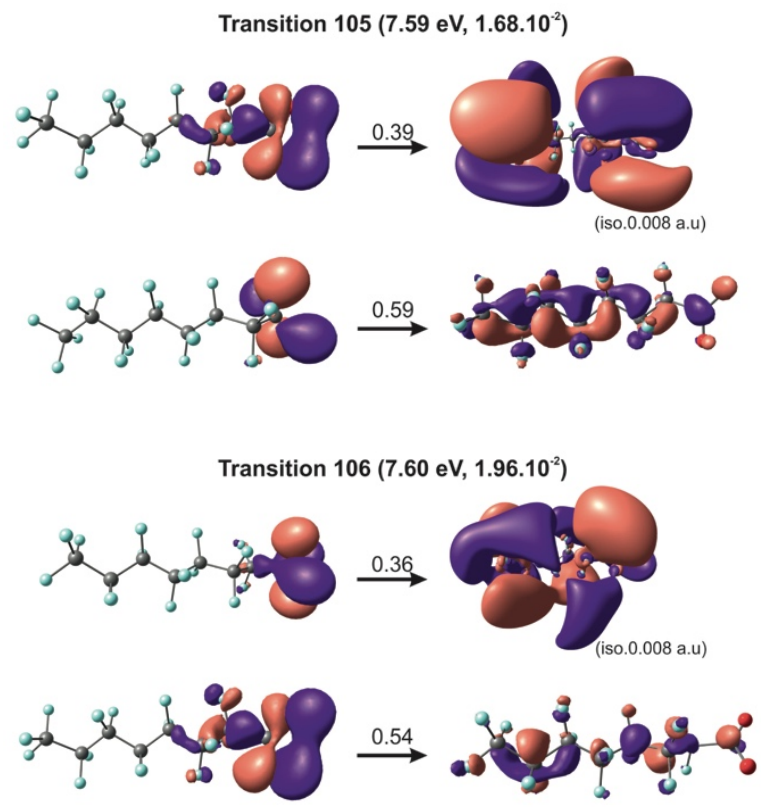

Transition $111\left(7.72 \mathrm{eV}, 2.48 .10^{-2}\right)$

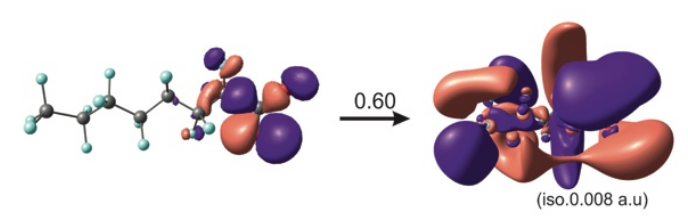

Transition $113\left(7.82 \mathrm{eV}, 1.50 .10^{-2}\right)$
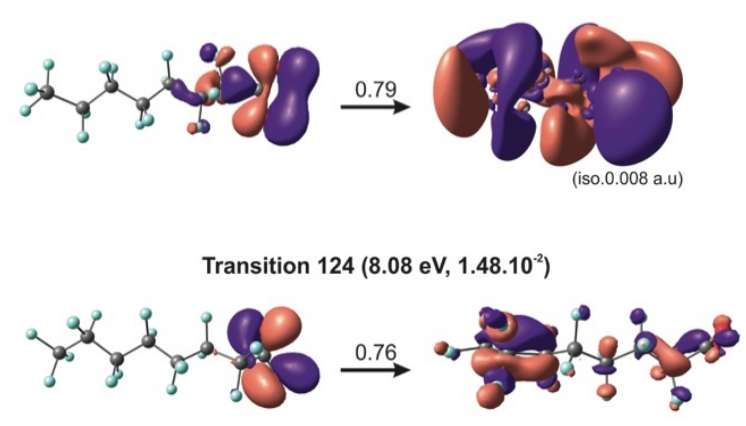

Transition $134\left(8.42 \mathrm{eV}, 2.94 .10^{-2}\right)$

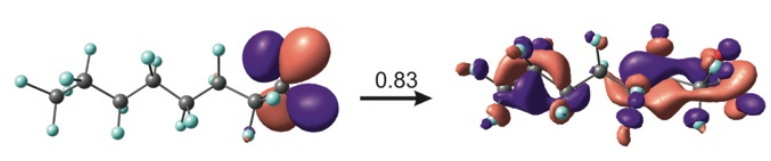

Transition $139\left(8.53 \mathrm{eV}, 3.3 .10^{-2}\right)$
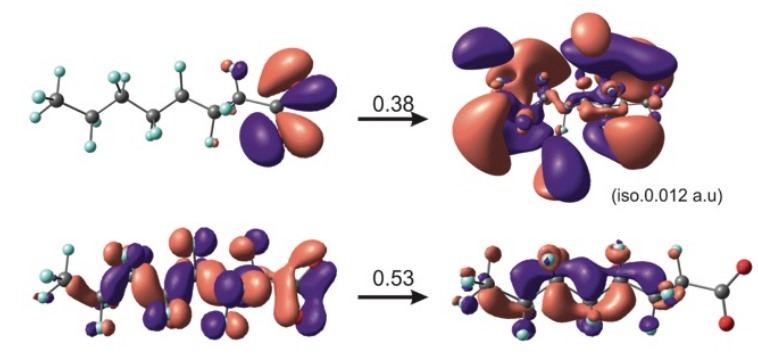

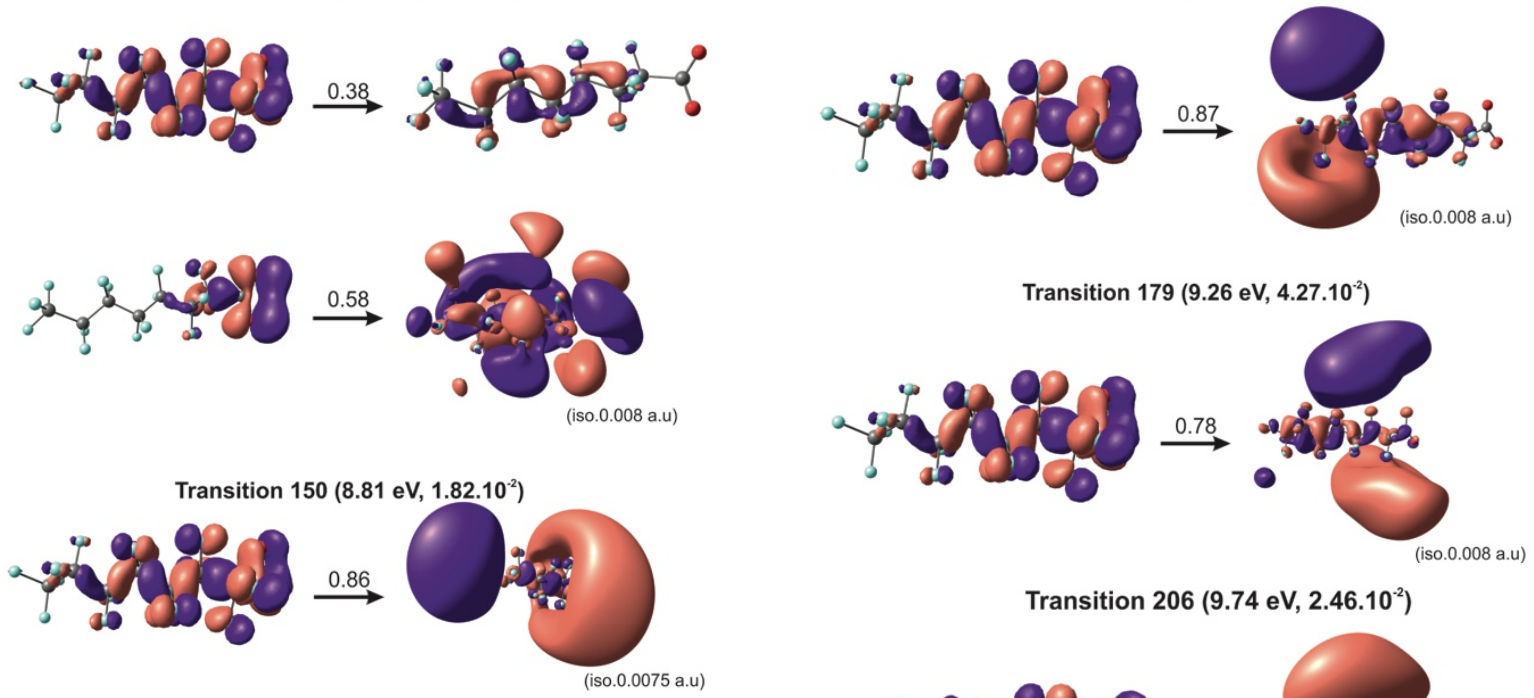

Transition $206\left(9.74 \mathrm{eV}, 2.46 .10^{-2}\right)$
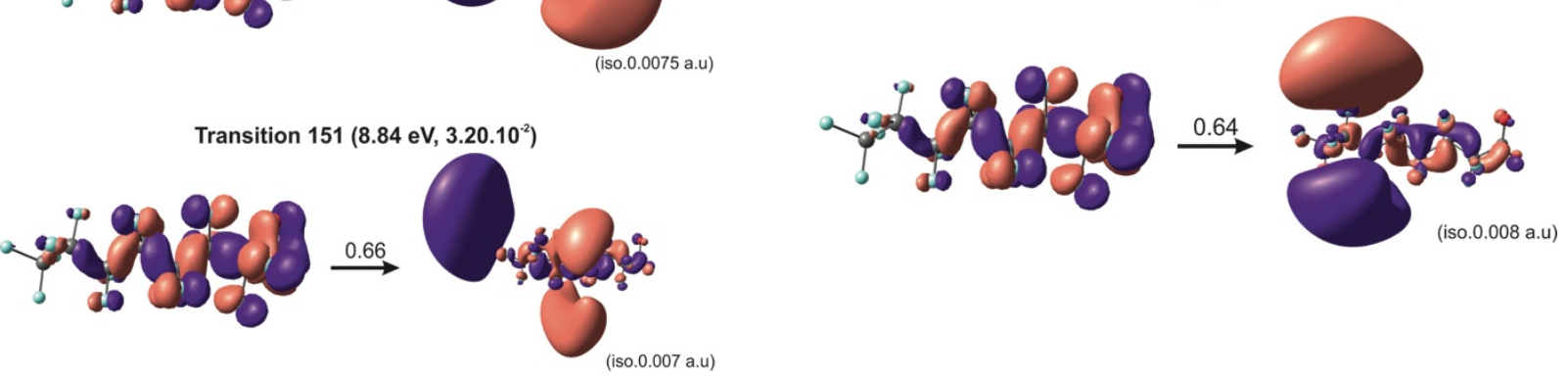

Figure S5: Natural transition orbitals for the main transitions. For each transition, the excitation energy and the corresponding oscillator strengths are indicated in parentheses and the associated weights above the arrows. If not stated otherwise, the isodensity surface is at 0.03 electrons $\AA^{-3}$. 